\title{
A Study on the Application of WeChat in ESP Training
}

\author{
Zhongwen Liu \\ Liaoning Police Academy, Dalian, China
}

\begin{abstract}
This exploratory research project is one of the research series on Ubiquitous Learning in English for Policing based on vocational scenarios, it focuses on the application of WeChat, the most popular software on smart phones among college students in China at present, in English for Specific Purpose (hereinafter referred to as ESP) training. The aim of applying WeChat is to improve the students' interests, motivation and efficiency of vocational field training. This paper presents previous and relevant studies, features of WeChat, and the implementation process of ESP training in a college English class via WeChat including lead in, text reading and scenario-based activities with emphasis on peer training, group training and face-to-face training details; analysis of the survey reveals that most students are in favor of using WeChat in English learning and training. Advantages and disadvantages of using WeChat in ESP training are also discussed.
\end{abstract}

Index Terms - WeChat, ESP training, application, scenario, ubiquitous learning

\section{INTRODUCTION}

The 2013 Survey of Online Learning conducted by the Babson Survey Research Group reveals the number of higher education students taking at least one online course has now surpassed 7.1 million (Babson Survey Research Group,2014). The figure illustrates the widespread of online learning in various disciplines, English for Specific Purposes (ESP), which belong to the area of English language Teaching (ELT), is considered as Applied ELT, since the goals and objectives and the syllabus of such a course are determined by the needs of a specific group of learners (Liza Sharmin, 2011). ESP learning covers a vast range of areas, including Business English, Technical English, Scientific English, English for medical professionals, English for waiters, English for tourism, English for Art Purposes, etc (Hutchinson, T. \& A. Waters 1987).

This study is one of the research series on Ubiquitous Learning in English for Policing based on vocational scenarios, which evolves with the development of the changing web technology and English for Elite Police courseware. The pedagogy mainly consists of a STARS instructional pattern focusing on situational experience and a virtual training pattern focusing on role-play different policing roles based on designed scenarios. The virtual training can be implemented through role-plays in class, vocational service practice after class or virtual training online after or in class, which is carried out via free software like QQ international or WeChat, a student determines to act as one of the police officers in the scenario and interact with service recipients acted by other participants including his/her peers, teachers, experts, policemen or foreigners through keying in words, sending audio or video messages. The program tries to construct a ubiquitous learning environment, in which any students can learn English or train vocational skills in English anytime, anywhere with any available devices as a step towards ecological service, resources sharing, individualized learning and lifelong learning. Implementation outcomes show that the students involved are interested in the vocation-related training and motivated in the language learning (Zhongwen Liu, 2013).

Technologies deployed shifted from computer software to LAN (Local Area Network) in the multi-media sound labs and the Internet, to the present Wi-Fi technology as a result of the rapid development of smart phones, as the survey conducted in March of 2013 and a year later showed that the percentage of smart phone users increased from 70\% to almost $100 \%$, which served as the overwhelming factor to shift our focus to the most popular software of smart phone users in China called WeChat.

WeChat is featured with the characteristic of ubiquitous learning, being available for almost every student at any time anywhere. WeChat is a mobile text and voice messaging communication service developed by Tencent in China, first released in January 2011. The app is available on Android, iPhone, BlackBerry, Windows Phone, Sybian and OS X platforms. Languages supported include Traditional/simplified Chinese, English, and so on. WeChat is supported on $\mathrm{Wi}-\mathrm{Fi}, 2 \mathrm{G}, 3 \mathrm{G}$ and $4 \mathrm{G}$ networks. According to Xinhua, WeChat total users reached 600 million worldwide in October 2013 (Wikipedia, 2014). WeChat provides multimedia communication with text messaging, hold-to-talk voice messaging, broadcast (one-to-many) messaging, photo/video sharing, location sharing, and contact information exchange. WeChat supports social networking via shared streaming content feeds and location-based social plug-ins ("Shake", "Look Around", and "Drift Bottle") to chat with and connect with local and international WeChat users. Photos can be taken and embellished with artistic filters, captions, and placed into a personal photo journal for sharing with other users. User data is protected via an on-demand contact list backup and retrieval to/from the cloud. WeChat 
claims to provide a social networking platform that emphasizes user privacy and fast response performance (Wikipedia, 2014). Some of the features of WeChat are shown in Figure 1.

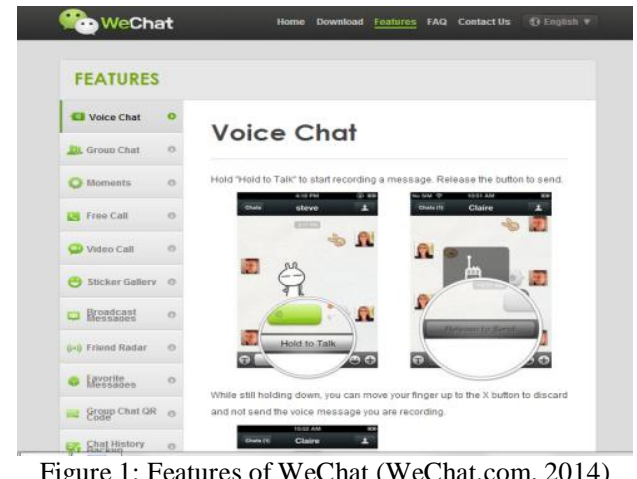

Similar research programs on the application of WeChat in English learning include constructing English learning environment on campus based on WeChat which mainly talks about the using of WeChat in class instruction (Hao Zhang, 2013), application of WeChat in college English teaching which explores the process and results of the implementation (Hongmei Jiang, 2013) and WeChat assisted language learning which effectively improved spoken English for English majors (Deng Pan, 2013). Six students from Suzhou Science and Technology Institute developed an interactive system in English class, enabling students to answer questions or interact with one another, all these activities were controlled by the teacher with a smart phone and the contents were projected on the large screen in the front of the classroom. The teacher could control his phone to send a discussion topic with MrQ of the system, play a video clip or show subtitles, start a group discussion and evaluate performances in each group and play a PPT or WritePad (Jingyu Wang, 2013). This study focused on how WeChat can be used in applying key words and expressions in English learnt in an integrated reading class by acting different vocation-related roles based on a designed scenario. The following specific research questions were addressed in this study so as to measure what can be done to improve the student satisfaction level in online learning.

1. Is WeChat their most frequent communication software?

2. Are the students interested in applying WeChat in their English learning?

3. What are the advantages of applying WeChat in their eyes?

4. What is the most serious problem when they use WeChat in their English learning?

5. What do they think of the new learning approach?

6. What is their favorite way of communicating in applying WeChat in English learning?

7. What are their suggestions or comments on English learning?

8. What are the advantages and disadvantages of applying WeChat compared with applying QQ under the same circumstances?

\section{METHODOLOGY}

\section{A. Research Design}

In 2012, we expounded the outline of the program, the design of scenarios and application of QQ International in EFL learning in the learning of Unit Four A Virtual Life of New College English (Integrated Reading Book 3) for three undergraduate classes majoring in Cyber Crimes Investigation, grade 2011, Liaoning Police Academy. Results of that study showed that $90 \%$ of the students rated the scenario-based instruction "better", $7 \%$ rated it as the same as, and $3 \%$ rated it "worse" than the traditional lecture and exercises class. 94\% of the students were "interested", 3\% were indifferent to, and 3\% were uninterested in learning English for Policing on English class. 92\% of the students believed scenario-based training "interesting and useful", 8\% thought it as "uninteresting and useless". Their comments on scenarios included: "make me more immersed in the realistic working situation", "more related to my future work", "a better platform on which I can show my potentials and experience different roles". Observations on the class also proved that students were more motivated and more actively involved in the training process, more concentrated on their peers' performances, more enthusiastic about scenario-based training. All the participants were energetic in solving real problems; those "Chinese policemen" focused more on vocational expertise expressed in English while "the foreigners" focused on respective cultures and social customs. Interviews with the students revealed positive attitudes toward the process-oriented assessment system. They thought the assessment "relaxing and fun", "emphasizing more on the improvement as a process rather than at a moment", "encouraging less fluent students to see their own improvement rather than compare with proficient counterparts" (Zhongwen Liu, 2012).

In order to get the comparison between the application of QQ International and WeChat, we decided to make a study with the same learning material and same scenario, but with the different software and our present students, three 
undergraduate classes majoring in Economic Crimes Investigation, grade 2013, Liaoning Police Academy. A Virtual Life describes how a person is addicted to online life, the key words and expressions mainly cover the advantages and disadvantages of surfing on line, which are related closely to the work of Internet security police officer and materials of Unit 9 Cyber Crimes in English for Elite Police, the textbook of English for Policing course.

The procedure of the instruction is shown in Figure 2:

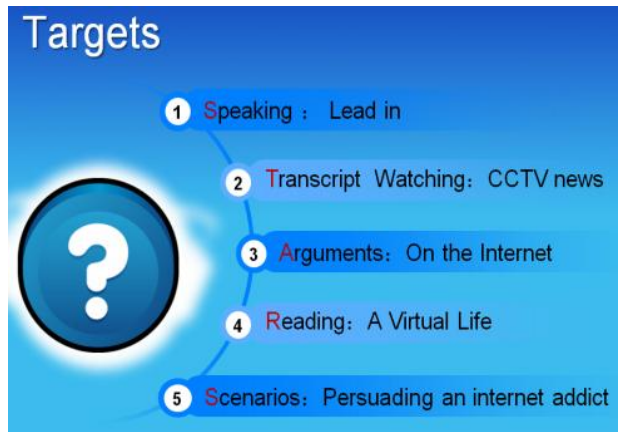

Figure 2: Arrangements of the learning procedure of Unit 4, text A: A Virtual Life

To arouse the students' interests to online activities, we first designed a "guess what I am describing" game to lead in the topic and related words and expressions. Then the class watched a video clip about online gambling and had a discussion on "what are the positive and negative effects of the Internet on my college life", the summary of these activity was that the internet was playing a more and more important role almost in every aspect of the college life, the art of using the internet lied in how the students could make a balance, how to take advantages of the technology, and trying to avoid being a victim. The reading of the text included explanation of new words like cyber, digital, electronic and virtual, analysis of the text structure and comprehension of each part to equip the students with some Internetrelated phrases and expressions. The last component of the teaching was the application of WeChat based on the scenario: Persuading an Internet Addict in order to train the students' ability to apply learnt knowledge in future workplace.

\section{B. Implementation Process}

The scenario was especially designed for the text containing title and time allocated, setting, characters (a Chinese police officer as a must), plots, objectives, assessment criteria and reference as shown in Table I (Zhongwen Liu, 2012):

TABLE 1

SCENARIO: PERSUADING AN INTERNET ADDICT

\begin{tabular}{|c|c|}
\hline Title & $\begin{array}{l}\text { Persuading an Internet Addict } \\
\text { (advantages and disadvantages of surfing online) } \\
\text { (5minutes) }\end{array}$ \\
\hline Setting & Place: Sky Internet Café, Zhongshan Square \\
\hline Characters & 1.An Internet Safety Administration Police Officer 2.A young boy \\
\hline Plots & $\begin{array}{l}\text { The Police Officer finds the boy surfing online at } 2 \text { am, check his ID first, and then persuade him not to spend too much time online, } \\
\text { The boy explains the reasons why he stays so late at first, but he is finally persuaded and goes back home. }\end{array}$ \\
\hline Objectives & $\begin{array}{l}\text { The boy is convinced that internet addict is harmful to his health and do no good for his family and study, he is grateful to the officer } \\
\text { and goes back home immediately. }\end{array}$ \\
\hline Assessment & $\begin{array}{l}\text { 1. English proficiency }(0.45) \\
\text { 2. key words and expressions }(0.20) \\
\text { 3. objectives achievement }(0.15) \\
\text { 4. professional skills } \quad(0.10) \\
\text { 5. self-improvement } \quad(0.10)\end{array}$ \\
\hline References & $\begin{array}{l}\text { 1. Hello, this is my certificate. Please show me your ID certificate. } \\
\text { 2. How could you concentrate on class tomorrow? } \\
\text { 3. Advantages of the internet: Faster and speedy communication; Information Resources; Entertainment, play games, watch films, } \\
\text { listen to music; Social networking, forums, qq messaging; Online services and e-commerce } \\
\text { 4. Disadvantages: Social problems, waste of time, spoil the health, waste of money, unwilling to connect to people; Theft of Personal } \\
\text { Information; Virus Threat; Pornography. } \\
\text { 5. Background information: Civilian Police persuade young abandon jump from internet addiction }\end{array}$ \\
\hline
\end{tabular}

All the students changed their WeChat icons according to the characters they had chosen to act, they either chose one icon from the photos uploaded in the group chat or searched one from the Internet of policemen, policewomen, suspects, witnesses or other characters in the scenario. To find one or more interactive partners, a student used the function of adding friends in different ways like searching by ID, QQ account, mobile phone contacts or scanning QR Code; 
searching people nearby; shaking mobile phone etc. Another function of WeChat we used is "Walkie Talkie": users can chat with a group of friends in a chat room. It's a real-time chat and even in the case of closing the phone's screen, realtime chat can still be going on.

The first activity was peer training, a student sent an invitation to a possible partner to start the training through text or audio chat, they could send links of some webpage, photos or video clips to each other, the teacher might check the recording or their audio chat to correct some mistakes and evaluate each student's performance according to the Assessment criteria listed in the scenario.

The second activity was group training in which several students set up a group and more than two students roleplayed the police officer and the boy, the teacher might participate one training with a virtual character, detect or prevent potential "runaways" from class, check one of the participant's chat records to determine who were more active and fluent than other students role-playing the same character, correct some mistakes in grammar, wording or expressions, evaluate each student's performance according to the Assessment criteria listed in the scenario.

The last activity was face-to-face role-play by two students followed by general evaluation and summary of the peer training and group training, some of the students paid attention to usage of the key words but didn't pay attention to realizing the aim, persuading the boy go back home willingly, some of the "officers" even used force or threat to use force to get the boy back home, while others made efforts to persuade the boy but made too many mistakes in speaking and spelling, all of which were evaluated in accordance with the assessment indexes, the evaluation score was noted down for the final evaluation at the end of the term. All the participants were required to write a reflection on the scenario-based training and to upload to their WeChat "moments" to share their viewpoints on the experience by answering the following reflection questions:

1. How did the WeChat-based training make you feel (compared to other traditional method like face-to-face roleplay)?

2. What was the most challenging thing that happened?

3. What will you do to better your performance next time in the similar situation?

4. What connections do you see between this experience and what you've learned in this unit?

5. How can your solutions apply to other situations in your future job?

Wechat "moments" are where the users commemorate their life and share their photos (by taking a photo or choosing existing photos) and thoughts (by sending plain texts) with their friends, which can be commented or sent to a new address.

\section{FINDINGS AND DISCUSSIONS}

A survey covering the 8 research questions was conducted on the next English class in Class 1, grade 2013, the answers were summarized as:

1. Is WeChat their most frequent communication software?

Yes, $86 \%$ of the students use WeChat, $14 \%$ use QQ.

2. Are the students interested in applying WeChat in their English learning?

Yes, $83 \%$ believe it is positive and interesting, $14 \%$ believe it is nothing special and $3 \%$ believe it is useless.

3 . What are the advantages of applying WeChat in their eyes?

$42 \%$ say they are not nervous, $22 \%$ think that it's fun and just like playing a game, $19 \%$ say they have time to think about the appropriate answer, $11 \%$ say they like to conceal their own identity, advantages mentioned by the rest of the students include: "I'm allowed to correct my own mistake before sending messages to my partner, more interested and motivated; it helps me to be immersed in the training and is a brand-new learning approach; I'm waiting anxiously for others to respond; it's interesting because I don't know what I'm going to get from others, an unexpected sound, a funny icon or a terrifying or mysterious picture?"

4. What is the most serious problem when they use WeChat in their English learning?

$71 \%$ don't think there are any problems, $17 \%$ think it as unnecessary, which can be done in the classroom, and $12 \%$ think it as too complicated.

5. What do they think of the new learning approach?

The average score is 89.25 (the highest score is 100).

6. What is their favorite way of communicating in applying WeChat in English learning?

$47 \%$ chose group chat, $33 \%$ chose one-to-one chat, $19 \%$ chose other method like sending and receiving text messages, no one chose face-to-face training, which shows a great interest at the beginning of the new application and the popularity of WeChat in English learning.

7. What are their suggestions or comments on English learning?

$53 \%$ wanted to have more time for CET 4 preparation; others wanted to have more spoken English training, more instructional innovations and more changes to play games while learning.

8. What are the advantages and disadvantages of applying WeChat compared with applying QQ under the same circumstances?

As far as audio chatting is concerned, QQ audio is sent and received simultaneously like making a call to someone while WeChat audio isn't sent and received simultaneously. Some say they don't have WeChat while others prefer the 
recording function of WeChat. Disadvantages of WeChat included: it can't be used on a computer, it's hard to hear the audio clearly with occasional Wi-Fi breakdown, some also complaint that there were students taking advantage of the training to chat in Chinese or playing with each other, but if they had used QQ, they would have focused on the conversation because they knew that their partner were waiting for the answers all the time.

\section{CONCLUSIONS AND PROSPECTS}

Please note that the real advantage of any web-mediated learning approach is learning anytime, anywhere and for anyone, this is true for WeChat, so besides the above mentioned applications in class, we have also applied WeChat in ESP learning after class. A WeChat group named English for Elite Police was set up in which the administrator send messages about the curricular arrangement, notices, tasks, discussion topics and answer questions in English, members also share their reflections, ideas, suggestions or stories on "moments".

WeChat is becoming the most popular software among college students at present as the rapid development of smart phones, application of WeChat in education is necessary and feasible. The most striking advantage of WeChat, compared with QQ International, is the non-synchronous chat and replay of the audio chat record, which allows teachers and students (including the user him/herself) to check the communication process to evaluate, correct or better the practice of interaction, it also allows the students to think for a while before interacting with other participants, which benefits especially for some introverted students or students whose English are not fluent enough to respond immediately. Another advantage of using WeChat is the active role it plays in the student-centered learning approach, students are more interested and involved in the learning process with the access of pictures, audio and video materials, and interactions with other participants, integrating self-directed learning with collaborative learning. Last but no means least, WeChat-based training provides real communication environment and simulated workplace for speaking and listening practice, enabling introverted students to enjoy the learning process and strengthen their creativity, motivation and critical thinking.

Like any new technical applications in a field, the initial research does arouse interests and curiosity on the one hand, on the other hand, WeChat can only be an supplementary tool but not a leading tool in English learning, teachers may also need patience and courage to make the double-edged sword contribute to education, how to guide and confine the students to use the smart phones only for studying, for instance, is one of the problems we found in the research especially at the beginning of the practice. One possible solution may lie in the check of their WeChat record during the study period, but the students may resent the potential invasion of their communication privacy, other solutions lie in the improvement of Wi-Fi technology and service. Compared with the other popular chat tool Yi-xin, developed by Netease.inc, WeChat does not provide the message received time as exactly as to hour, minute and second, making the comparison of responding time more difficult; what's worse, WeChat does not display whether the sent message is read or not by the receiver.

What we have done is just a tip of the iceberg in using WeChat, we will enlarge our research into the training of speaking, listening, writing and translating, especially in the after-class platform so as to improve the flexibility of English learning on which students can note down their reflections, share their learning experiences with peers and teachers, or upload their homework. Teachers can assign learning tasks through sending pictures, texts or audio records, evaluate or comment on their performances. Based on our previous studies on the scenarios, virtual training via QQ International and the present WeChat, we are trying to provide students a ubiquitous learning environment, enabling them to learn English and train their professional competence anytime, anywhere with any available device. One of the forthcoming researches will focus on flipped classroom to apply learnt English in scenario-based training, while the traditional language learning will be recorded by the teacher and uploaded to the QQ International group for the students to learn by themselves before class. The flipped model takes the advantage of the micro-course, online learning community and the interactive function of the classroom, making the best use of technology to learn before or after class what can be learnt by the students themselves with the guidance of the instruction video, and also the best use of the teacher and the students in class to interact and collaborate with all the participants to practice vocational skills because applying knowledge is forever the ultimate goal of learning.

\section{ACKNOWLEDGMENT}

The author wishes to thank experts and judges of Liaoning Association of Higher Education for their support of the Exclusive Research Projects on Foreign Language Teaching and Learning Reform for Institutions of Higher Learning No. WYYB13178: A Study on the Application of WeChat in ESP Training. The paper is also the research results of the College Teaching Reform Research Project of Liaoning Province (2014) No. UPRP20140574: Multi Models to Develop College Students' 3C Abilities through Network College English Teaching and Learning Based upon Questions and the teaching reform project of Liaoning Police Academy, 2014: A Case Study on the Application of Micro-course, QQi and Simulated Training in Flipped EFL Classroom through Intercollegiate Collaboration.

\section{REFERENCES}


[1] Babson Survey Research Group. (2014). Babson Study: Over 7.1 Million Higher Ed Students Learning Online. http://www.prnewswire.com/news-releases/babson-study--over-71-million-higher-ed-students-learning-online-240277461.html (accessed 7/4/2014).

[2] Deng Pan. (2013). A Study on the Suitability of Micro-Leaning Community in English Mobile-learning. Journal of Hubei University of Science and Technology, 33.9, 103-105.

[3] Hao Zhang. (2013). Construction of English Learning Environment on Higher Institutes Campus Based on WeChat. Cultural and Teaching References, 12, 183-184.

[4] Hongmei Jiang. (2013). Application of WeChat in College English Teaching. Journal of Shunde Polytechnic, 11.2, 52-54.

[5] Hutchinson, T. \& A. Waters. (1987). English for Specific Purposes: A learning-centered approach. Cambridge: Cambridge University Press

[6] Jingyu Wang. (2013). WeChat Can Be Played in This Way: Geek College Students Set up Interactive System in English Class via WeChat, Integrating Social Participation and Real-time into Class. http://www.36kr.com/p/203431.html (accessed 3/8/2014).

[7] Liza Sharmin. (2011). Analyzing 'needs' for designing a specific English language course for medical students in Bangladesh. Stamford Journal of English, 6, 249-260.

[8] WeChat.com. (2014). http://www.wechat.com/en/features.html\#voice (accessed 25/7/2014).

[9] Wikipedia. (2014). WeChat. http://en.wikipedia.org/wiki/WeChat (accessed 13/4/2014).

[10] Zhongwen Liu. (2012). Construction and Application of Scenarios in College EFL Learning. International Forum of Teaching and Studies, 8.2, 32-40.

[11] Zhongwen Liu. (2013). Virtual Policing in English: A Trainee-centered Pedagogy for Web-mediated Curricular Learning and Field Training. Journal of Software, 8.2, 344-350.

Zhongwen Liu, BA of English, Liaoning Normal University, 1993, Master of Engineering, Dalian Maritime University, 2005. He is a professor in Liaoning Police Academy and a candidate for the Police Liaison Officers of the Public Security Ministry of China, the author of English for Elite Police, Press of Chinese People's Public Security University, 2009 and 4 EI indexed papers. He coined VPIE and Virtual Service Learning pedagogies with research interest in web-mediated instructional technology. 